\title{
Diagnosis of Human Visceral Leishmaniasis by PCR Technique in Iraq
}

\author{
تشخيص الحمى السوداء باستخدام تقتية سلسلة تفاعل البلمرة في العراق
}

\author{
Abdullah M. Qadir Mushrik K. Abood *Tural Y. Bakir \\ Gaith L. Al-Azzawi, Enas A. Rashad
}
Biotechnology Research Center, Al-Nahrain University
*Foundation of Technical Education, College of Health and Medical
Technology

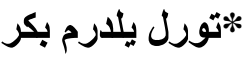

$$
\begin{aligned}
& \text { مشرق كامل عبود }
\end{aligned}
$$

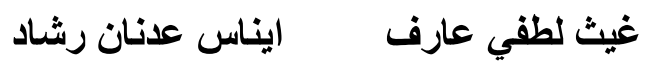

$$
\begin{aligned}
& \text { عبدالله مصطفى قادر } \\
& \text { مركز بحوث التقنيات الاحيائية / جامعة النهرين } \\
& \text { * كلية التقنيات الطبية و الصحية / هيئة التعليم التقني /لفئي التهين }
\end{aligned}
$$

\begin{abstract}
:
In the present study, 93 blood samples and 20 bone marrow aspirates from 93 patients with clinical symptoms suggestive of visceral leishmaniasis (VL) from three hospitals in Baghdad during the period October 2005 - May 2006, were screened using molecular and serological techniques. Samples that were negative $(N=50)$ in parasitological and serological tests were used as controls. Of the 93 samples analyzed by ELISA technique, 19 samples $(17.7 \%)$ gave positive culture result on NNN medium. However, when the technique was combined with molecular characterization by PCR, 7 samples $(36.8 \%)$ gave a positive result. Nineteen patients with Leishmania parasites in bone marrow cultures showed PCR amplification of the correct band, as did the seven bone marrow aspirates positive for Leishmania. None of the negative controls tested using PCR or in an ELISA assay. These results indicate that PCR could replace the conventional parasitological examination in the diagnosis of leishmaniasis since it provides very satisfactory results with clinical samples.
\end{abstract}

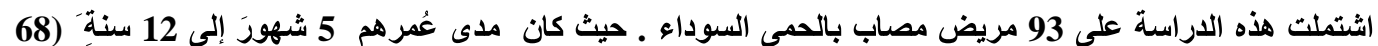

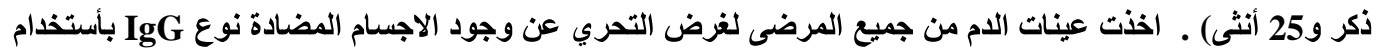

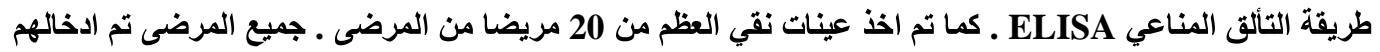

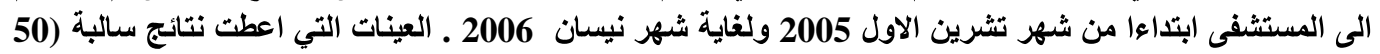

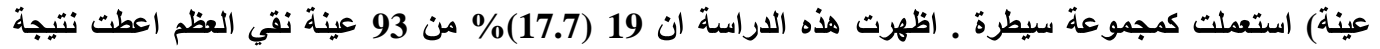

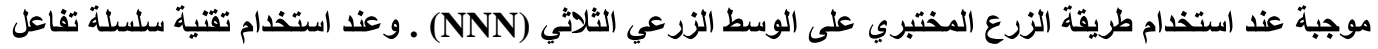

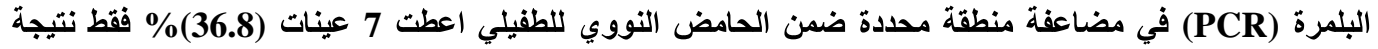

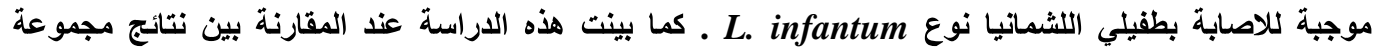

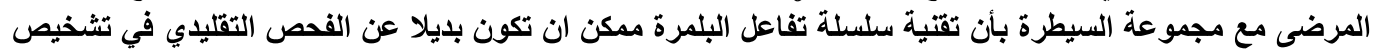
مرض الحمى السوداء في العراق . 


\section{Introduction:}

The etiological agents of visceral leishmaniasis (VL) are Leishmania chagasi (New World), L. infantum (Mediterranean region) and L. donovani (Indian subcontinent and Africa) [1]. Visceral leishmaniasis (VL) is generally fatal if untreated [2] and its clinical symptoms include mainly intermittent fever, enlargement of the spleen, and pancytopenia. The diagnosis of leishmaniasis is based on clinical and epidemiological characteristics, on identification of the parasite during microscopic examination, or on indirect detection through serological tests. The serodiagnosis of leishmaniasis can be done using several methods. Indirect immunofluorescent assays (IFA) were the preferred method up to 1974 [3]. Since then, counter-current immunoelectrophoresis and enzyme-linked immunosorbent assays (ELISA) have proven to be useful in the diagnosis of this disease [4]. However, these three methods have several limitations, including a low sensitivity and specificity. The development of the polymerase chain reaction (PCR) [5] has led to the introduction of procedures for the detection and genetic characterization of Leishmania [6]. Since its introduction, PCR has been widely used to diagnose human and canine VL because of its high sensitivity and specificity $[7,8,9,10]$. PCR has also been used to diagnose VL in epidemiological studies and to detect the parasite in potential vectors and reservoirs. In addition, PCR can be used to investigate the phylogenetic relationships among Leishmania strains and species [11]. The increasing importance of VL in man and its high rate of lethality in the metropolitan region, mean that a rapid, relatively simple method is required for the routine diagnosis of VL [12]. The aim of the present study was use PCR assay for the diagnosis of VL using aspirated bone marrow samples.

\section{Materials and Methods}

Ninety three patients with clinical symptoms of VL were studied. Ninety three blood samples and twenty bone marrow aspirates from these patients were used in molecular and serological analyses. Blood from 50 volunteers from the same area served as negative controls. Patients' evaluation including history and physical examination by the consultant medical staff at the hospitals. Laboratory diagnosis of the disease was confirmed by determination of anti- $L$. donovani IgG antibodies in the sera of patients using ELISA techniques (IVD Research Inc. Carlsbad, CA92008 USA). Cells in bone marrow aspirates were cultured in NNN medium supplemented with $10 \%$ fetal calf serum and incubated at $24-25^{\circ} \mathrm{C}$ for 30 days. Parasites were detected in bone marrow cells by microscopic examination of Giemsa-stained slides. DNA extracted from promastigote (using CinnaGen $\mathrm{DNP}^{\mathrm{TM}}$ ) was used for PCR. The reactions were done in a total volume of $25 \mu 1$ containing $17.7 \mu 1$ 1x PCR MIX, $0.3 \mu 1$ of Taq-DNA polymerase, and $5 \mu \mathrm{l}$ of the DNA was added to the mixture. The PCR amplification was done in a DNA thermocycler (eppendorf) using 1 cycle of $95^{\circ} \mathrm{C}$ for $180 \mathrm{sec}, 63^{\circ} \mathrm{C}$ for $30 \mathrm{sec}$, and $72^{\circ} \mathrm{C}$ for $60 \mathrm{sec}$. Followed by 35 cycles of $93^{\circ} \mathrm{C}$ for $40 \mathrm{sec}, 93^{\circ} \mathrm{C}$ for $40 \mathrm{sec}$, and $72^{\circ} \mathrm{C}$ for 60 sec. The PCR was done using CinnaGen Leishmania sp. Positive control included in each experiment. The amplification products were analyzed by electrophoresis in agarose gels followed by ethidium bromide staining.

\section{Results}

Patients enrolled in this study had characteristic signs and symptoms of VL including fever, hepatosplenomegaly, anemia, leucopenia and hyper-globulinaemia. All cases were hospitalized patients, and their age range was 5 months to 12 years at the time of admission. There were (68 males and 25 females). DNA purified from patients samples yielded an 
amplification product of the expected size (800 bp) according manufacturer instructions.

Of 93 blood samples analyzed by ELISA technique, 19 (17.7\%) sample gave positive culture result on NNN medium and showed the expected product in agarose gels. However, when PCR was followed by electrophoresis, 7 samples that were negative by visual inspection of the agarose gels gave positive signals. All the PCR products were confirmed as L. infantum Figure (1). Table (1) compares the PCR results with the parasitological and serological tests.

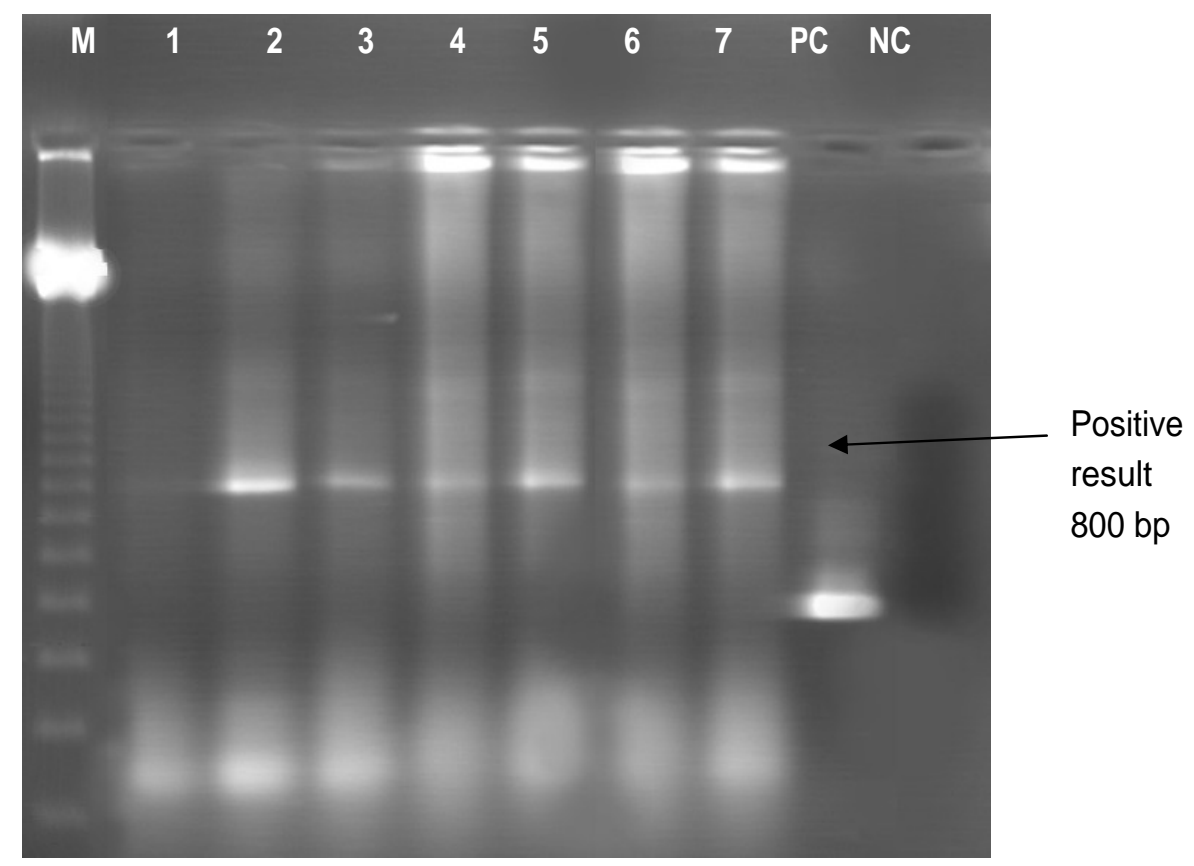

Figure (1) : PCR reaction for diagnosis of leishmaniasis of samples of bone marrow aspirate of patients with visceral leishmaniasis, $2 \%$ agarose gel electrophoresis stained with ethidium bromide. M, 123-bp DNA ladder; L. infantum amplified DNA (lanes 1, 3, $4,5,6,7)$; positive control (PC); negative control (NC).

Table (1): Results for the diagnosis of leishmaniasis using different techniques in samples from patients with clinical symptoms of visceral leishmaniasis (VL) and their corresponding controls.

\begin{tabular}{|c|c|c|}
\hline Technique & Healthy patients & Patients with VL \\
\hline $\begin{array}{c}\text { Direct observation of bone } \\
\text { marrow }\end{array}$ & - & 7 \\
\hline Culture & 0 & 19 \\
\hline Serology & 0 & 93 \\
\hline PCR & 0 & 7 \\
\hline
\end{tabular}

\section{Discussion}

Visceral leishmaniasis in Iraq is endemic and there has been an increase in the number of cases during the last years. More than 3000 cases of VL were reported in 2004 
from different regions of Iraq. The majority were from the southern regions (bordering Iran), less in the middle, and few cases from northern regions. Visceral leishmaniasis cases in Iraq reported in all months of the year but mostly reported between December 2007-March 2008 [13].

Currently, the diagnosis of VL is based on clinical and epidemiological characteristics, parasitological analysis and the detection of anti-Leishmania antibodies. Confirmatory laboratory tests, which are rarely used, are restricted to a few reference centers and are not available to most patients. Direct microscopic identification of Leishmania is simple and cheap, but its sensitivity is very low, even when done by trained personnel [14]. Axenic culture is highly sensitive but requires special facilities, trained personnel, and is subject to contamination. Since some Leishmania strains are difficult to grow in the laboratory, parasite culture has been restricted to reference centers and used only for research purposes [15]. Serological tests are frequently used in epidemiological surveys of leishmaniasis and other parasitic diseases. One of the difficulties in defining the sensitivity and specificity of any test is the need for a gold standard that can correlate with the direct detection of the parasite [16]. Immunological tests, such as IFA and EUSA show cross-reactivity with other diseases and do not distinguish between past and present infections. On the other hand, PCR, although considered highly sensitive, fails to distinguish viable parasites from degenerated ones. In addition, PCR products may be obtained from other kinetoplastids not normally expected to be found in humans [17]. In the present study, we used PCR with specific primers from the conserved region of Leishmania minicircles [6]. This approach is very useful for diagnosing VL and can provide a better understanding of the epidemiology of visceral and cutaneous leishmaniasis (C) in endemic areas [12,18]. Campino et al, (2000) used PCR to detect Leishmania DNA in peripheral blood obtained from HIV-positive patients with co-infection, but the species of Leishmania involved was not identified [7].

Recent studies document the emergence of new Leishmania foci and the coexistence of multiple Leishmania species in the same geographic locale, including much of northern Africa [19]. We recommend that treatment protocols, particularly in areas of coexistence, be predicated on diagnosis of not only the clinical form CL versus VL but additionally the disease causing species

\section{References}

1. World Health Organization (1990). Control of Leishmaniasis. Report of a WHO Expert Committee. Technical Report Series No. 793. World Health Organization, Geneva, Switzerland.

2. Meinecke, C.K., Schottelius, J., Oskam, L. and Fleischer, B. (1999). Congenital transmission of visceral leishmaniasis (Kala Azar) from an asymptomatic mother to her child. Pediatrics 104: e65.

3. Zuckerman, A. (1975). Current status of the immunology of blood and tissue Protozoa. I. Leishmania. Exp. Parasitol. 38: 370-400.

4. Mukerji, K., Roy, S., Mukhopadhyay, P., Gupta, P.K. and Ghosh, D.K. (1984). Evaluation of different subcellular fractions of Leishmania donovani for immunodiagnosis of visceral leishmaniasis. Indian J. Exp. Biol. 22: 120-122. 
5. Saiki, R.K., Gelfand, D.H. and Stoffel, S. (1988). Primer-direct enzymatic amplification of DNA with a thermostable DNA polymerase. Science 239: 487-491.

6. Degrave, W., Fernandes, O., Campbell, D., Bozza, M. and Lopes, U. (1994). Use of molecular probes and PCR for detection and typing of Leishmania - a mini review. Mem. Inst. Oswaldo Cruz 89: 463-469.

7. Campino, L., Cortes, S., Pires, R., Oskam, L. and Abranches, P. (2000). Detection of Leishmania in immunocompromised patients using peripheral blood spots on filter paper and the polymerase chain reaction. Eur. J. Clin. Microbiol. Infect. Dis. 19: 396-398.

8. Silva, E.S., Pirmez, C., Gontijo, C.M.F., Fernandes, O. and Brazil, R.P. (2000). Visceral leishmaniasis in the crab-eating fox (Cerdocyon thous) in south-east Brazil. Vet. Rec. 147: 421-422.

9. Silva, E.S., Gontijo, C.M.F., Pirmez, C., Fernandes, O. and Brazil, R.P. (2001). Short report: detection of Leishmania DNA by PCR on blood samples from dogs with visceral leishmaniasis. Am. J. Trop. Med.Hyg. 65: 896-898.

10. Silva, E.S., Pacheco, R.S., Gontijo, C.M.F., Carvalho, I.R. and Brazil, R.P. (2002). Visceral leishmaniasis caused by Leishmania (Viannia) braziliensis in a patient infected with human immunodeficiency virus. Rev. Inst. Med. Trop. S. Paulo 44: 145-149.

11. Cupolillo, E., Brahim, L.R., Toaldo, C.B., Oliveira-Neto, M.P., Brito, M.E.F., Falqueto, A., Naiff, M.F. and Grimaldi Jr., G. (2003). Genetic polymorphism and molecular epidemiology of Leishmania (Viannia) braziliensis from different hosts and geographic areas in Brazil. J. Clin. Microbiol. 41: 3126-3132.

12. Silva, E.S., Gontijo, C.M.F., Pacheco, R.S., Fiuza, V.O.P. and Brazil, R.P. (2001b). Visceral leishmaniasis in the metropolitan region of Belo Horizonte, State of Minas Gerais, Brazil. Mem. Inst. Oswaldo Cruz 96:285-291.

13. Rasheed, Z. N. (2004) Leishmaniasis in Iraq. Leishmania and zonotic disease section. Communicable Disease Control Center CDC/Baghdad/Iraq.

14. Mathis, A. and Deplazes, P. (1995). PCR and in vitro cultivation for detection of Leishmania spp. In diagnostic samples from humans and dogs. J. Clin. Microbiol. 33: 1145-1149.

15. Aviles, H., Belli, A., Armijos, R., Monroy, F.P. and Harris, E. (1999). PCR detection and identification of Leishmania parasites in clinical specimens in Ecuador: a comparison with classical diagnostic methods.J. Parasitol. 85: 181-187.

16. Dye, C., Vidor, E. and Dereure, J. (1993). Serological diagnosis of leishmaniasis: on detecting infection as well as disease. Epidemiol. Infect. 110: 647-656.

17. Smyth, A.J., Ghosh, A., Hassan, M.Q., Basu, D., De Bruijn, M.H., Adhya, S., Mallik, K.K. and Barker, D.C. (1992). Rapid and sensitive detection of Leishmania kinetoplast DNA from spleen and blood samples of kala-azar patients. Parasitology 105: 183-192.

18. Passos, V.M.A., Falc?o, A.L. and Katz, N. (1999). Urban American cutaneous leishmaniasis in the metropolitan region of Belo Horizonte, Minas Gerais State, Brazil. Mem. Inst. Oswaldo Cruz 85: 243-244.

19. Gramiccia M, Ben-Ismail R, Gradoni L, Ben Rachid MS, Ben Said MA. (1991). Leishmania infantum enzymatic variant, causative agent of cutaneous leishmaniasis in north Tunisia. Trans R Soc Trop Med Hyg. 85:370-1. 